\title{
Assessment of Knowledge and Practice of Childhood Routine Immunization among Mothers/Caregivers attending Primary Health Care Centres in Benin City, Edo State, Nigeria
}

\author{
*1'UWAIBI, NE; ${ }^{2}$ AKHIMIENHO, IK \\ ${ }^{*}$ Department of Community Health, college of clinical sciences, Edo University Iyamho, Edo state Nigeria \\ ${ }^{2}$ Department of Paediatrics, College of clinical sciences, Edo University Iyamho, Edo state Nigeria \\ *Corresponding Author Email: noel.uwaibi@gmail.com
}

\begin{abstract}
The ultimate goal of immunization is to reduce the incidence of vaccine preventable diseases by attaining high levels of routine immunization coverage with potent vaccines administered at the appropriate ages and at the right intervals. This study assessed the knowledge and practice of childhood routine immunization among mothers/caregivers attending Primary Health Care Centers in Benin City, Edo State. A descriptive cross-sectional study involving 640 females whose wards were receiving immunization in 35 PHCs in Benin City was carried out. Mothers who met the inclusion criteria were recruited using a pre-tested interviewer administered structured questionnaires using a multistage sampling technique. Relationship between dependent and independent variables was determined using logistic regression analysis, at $95 \%$ confidence interval and p-values level less than 0.05 were considered significant. Results shows that all the caregivers were aware of immunization. $498(77.8 \%)$ with the media being as source of information. A higher proportion of respondent (44.8\%) had good knowledge while (38.6\% and 12.6\%), fair and poor knowledge of immunization respectively. BCG and OPV were the most known vaccines $(89.1 \%)$, followed by HBV (77.8\%), DPT and PENTA were known by $70.6 \%$ and $66.1 \%$ of respondents respectively. This study revealed good knowledge of immunization amongst the caregivers and good practice with regards to the actual purpose of immunization.
\end{abstract}

DOI: $\underline{\text { https://dx.doi.org/10.4314/jasem.v24i10.1 }}$

Copyright: Copyright $(\subset) 2020$ Uwaibi and Akhimienho. This is an open access article distributed under the Creative Commons Attribution License (CCL), which permits unrestricted use, distribution, and reproduction in any medium, provided the original work is properly cited.

Dates: Received: 10 August 2020; Revised: 16 September 2020; Accepted: 29 September 2020

Keywords: immunization, mothers, knowledge, under-five, practice

Immunization is the process by which a person is made resistant to an infectious agent by the application of vaccines. Vaccine Preventable Diseases are a major cause of illness and deaths especially in developing countries and vaccines can significantly reduce childhood mortality and morbidity. (Salah et al., 2015) In Nigeria, immunization services (routine or supplemental) are provided through the primary health care system by the government to the populace. (Ekure et al., 2013) Routine immunizations are nationally scheduled regular administrations of vaccine dosages to infants at specified ages and require parents/caregivers taking the children to the health facility to receive age-appropriate doses of the antigens. This is done on specific days of the week to reduce vaccine wastage since most of the vaccines are supplied in multi-dose vials. (Zangeneh et al., 2011) Five visits are recommended by the National Programme on Immunization (NPI) to the health facility to enable the child receive one dose of Bacille Calmette Guerin (BCG) and Hepatitis B at birth, three doses of Oral Polio Vaccine (including one IPV), and three doses of Pentavalent vaccine, at six, ten and fourteen weeks and one dose of measles vaccine and yellow fever given at nine months of age. (Scott et al., 2014; FMOH, 2009) It is of importance that a child should receive all immunization at the appropriate ages and intervals in order to ensure maximal protection from vaccine preventable diseases. (Adedire et al., 2016; Sadoh and Eregie, 2009) The percentage of children who have receive the requisite number of vaccine doses irrespective of the age at receipt of the vaccine is used to calculate and determine vaccination coverage (Abdullraheem et al., 2011) and the third dose of pentavalent vaccine, is the key indicator to measure immunization programme coverage. (Mantua et al, 2016) At each visit the mother or caregivers is given appointment dates (written on the child's registration card) for the next vaccination. (Hannan, 2014) Despite this approach, knowledge, level of education, and religion of mothers have been reported as major contributory factors to low immunization coverage Nigeria, Africa and Asia (Onsomu et al., 2015; Maina et al., 2013; Subani et al., 2015; Uzochukwu et al., 2004; Beaven et al., 2016; PAN, 2012) showed that mothers' knowledge, 
attitudes and practices on childhood immunization were at low levels. A research carried out in Nigeria reported that incomplete vaccination was due to maternal knowledge and attitudes, while partial immunization with multidose vaccines was more linked to problems with vaccination services. These factors have contributed to a fall in immunization coverage and upsurge of VPDs as well as failure to achieve the millennium development goal (MDG), and this has further worsened the country's infant mortality rate of $69 / 1000$ and under five mortality of 128/1000. (NDHS, 2013) This study assessed the knowledge and practice of childhood routine immunization among mothers/caregivers attending primary health care centers in Benin City, identified factors contributing to mother's/ caregiver's knowledge of immunization and areas needing attention.

\section{MATERIALS AND METHODS}

This was a descriptive cross-sectional study carried out in 35 Primary Health Care facilities across the three Local Government Areas in Benin City, Edo State, Nigeria. It was conducted among 640 mothers who met the inclusion criteria using a multistage sampling technique. Sample size were determined using the (Cochrane, 1977) formula for studying single proportion. $\mathrm{n}=(\mathrm{Z})^{2} \mathrm{pq}($ deff $) / \mathrm{d}^{2}$ where $\mathrm{p}$ is prevalence of $51.0 \%$, the proportion of mother's knowledge of immunization from a study carried out in 2019 in Lagos, Nigeria. (Adefolalu et al., 2019) The respondents were selected using multistage sampling technique consisting of three stages from the 3 LGA (Oredo, Ikpoba Okha and Egor. Two wards were selected from each of the 3 LGAs (Oredo, Egor, and Ikpoba Okha) using simple random sampling technique, by balloting from the list of wards obtained from the PHC department in each LGA, making a total of 6 wards, then all the PHCs within the selected 6 wards were used for the study. Systematic sampling technique was used to select the mothers/caregivers, after determining the sampling internal and this was used to select the mothers until the sample size was achieved.

Survey questionnaire for mothers/caregivers: A pretested structured interviewer administered questionnaire was retrieved, screened for completeness, coded and entered into the IBM statistical package for social sciences (SPSS) statistics 21.0 software. The categorical variables were presented as frequencies and percentages while numerical variables that were normal in distribution was expressed as mean (standard deviation). The Chisquared test of association was used to test statistical association between socio-demographic variables of the respondents and the knowledge of immunization, knowledge and practice of immunization. The Fisher's exact test was used in instances where the total expected cell frequencies less than five is more than $20 \%$. The binary logistic regression was modelled to explore and identify significant predictors of routine immunization services at the Primary Health Facilities in the LGAs. The level of significance was set at $\mathrm{p}<$ 0.05 . Socio-economic classes of the respondents were scored based on the mother's/caregivers' level of education and their husband's occupation. Six questions in the maternal questionnaire were used to assess knowledge. Each correct response on knowledge was given a score 1 while incorrect response a score of 0 , giving a maximum and minimum score of 0 and 6 , respectively. It was converted to percentages and classified as: Poor knowledge: less than 50\%, Fair knowledge: 50 $74.9 \%$ and Good knowledge: $75 \%$ and above. Ethical clearance to conduct this research was sought and obtained from the University of Benin Teaching Hospital Ethics and Research Committee. Permission was sought from the Permanent Secretary, Edo State Hospital Management Board and Chairpersons of the Local Government Areas. Institutional permission was sought and obtained from the Primary Health Care Coordinators, and Heads of the health facilities. Health education was given to the mothers after the data collection and those whose child were ill referred to the hospital.

\section{RESULTS AND DISCUSSION}

The socio-demographic characteristics of mother/caregivers is presented in table 1. Three hundred and thirty-two $(51.9 \%)$ were $30-39$ years old with mean age and (SD) of respondents was 32.1 (7.1). Six hundred and twenty-nine $(98.3 \%)$ were the mothers of the index child, 17 (2.6\%) were single, with $409(63.9 \%)$ having secondary level of education. All the care givers (Table 2) were aware of immunization. Six hundred and seven $(94.8 \%)$ reported healthcare practitioners as their source of information, with BCG and OPV the most known vaccine mentioned by 570 $(89.1 \%)$ of the caregivers then DPT and PENTA as mentioned by $452(70.6 \%)$ and 423 (66.1\%) respectively.

Three hundred and fifteen (49.2\%) were aware of seven or more vaccines while $610(95.3 \%)$ stated that nine months was the age of completion of vaccination while some caregivers were of the opinion $21(3.3 \%)$ that immunization makes children grow fast. In figure 1, we observed that three hundred and twelve (48.8\%) of the caregivers had good knowledge scores while $247(38.6 \%)$ had poor knowledge while 81 (12.6\%) had fair knowledge. 
Table 1: Socio-demographic characteristics of mother/caregivers

\begin{tabular}{lll}
\hline Variable & $\begin{array}{l}\text { Frequency } \\
(\mathbf{n = 6 4 0 )}\end{array}$ & Percent \\
\hline Age (years) & 7 & \\
$<20$ & 7 & 1.1 \\
$20-29$ & 232 & 36.3 \\
$30-39$ & 332 & 51.9 \\
$40-49$ & 59 & 9.2 \\
$\geq 50$ & 10 & 1.6
\end{tabular}

\section{Relationship with \\ child}

Mother

Grand parents

Aunt

Marital status

Single

Married

Cohabiting

Separated/ divorced

Widowed

Household size

$\leq 4$

$5-8$

$\geq 9$

Level of education

No formal education

Primary

Secondary

Tertiary

Employment status

Employed

Unemployed

Occupation $(\mathbf{n}=555)$

Professional 23

Middle class

Unskilled

Spouses' level of education* $(n=632)$

No formal education

Primary

Secondary

Tertiary

Professional

Middle class

Unskilled

$629 \quad 98.3$

$9 \quad 1.4$

2

1.4

0.3

$17 \quad 2.6$

$615 \quad 96.1$

$1 \quad 0.2$

$4 \quad 0.6$

$3 \quad 0.5$

$264 \quad 41.3$

$357 \quad 55.8$

$19 \quad 3.0$

$6 \quad 0.9$

$180 \quad 28.1$

$409 \quad 63.9$

$45 \quad 7.0$

$555 \quad 86.7$

$85 \quad 13.3$

$23 \quad 4.1$

$166 \quad 29.9$

$366 \quad 66.0$

$1 \quad 0.2$

$\begin{array}{ll}68 & 10.8\end{array}$

$452 \quad 71.5$

$111 \quad 17.5$

Mean age $=32.1 \pm(7.1)$ years; *Included information of spouses of

single caregivers who contributed financially to the upkeep of the index child.

All the caregivers reported vaccinating the index child. Six hundred and twenty-five $(97.7 \%)$ presented with their vaccination cards while $15 \quad(2.3 \%)$ had vaccination cards but presented without them. Six hundred and thirty (98.4\%) of the index children had received $\mathrm{BCG}$, all received the first doses of OPV, PENTA and PCV and smaller proportion received measles and yellow fever vaccines [118 $(72.4 \%)$ and $119(73.0 \%)$ respectively]. There was no statistically significant association between the age of the child and the caregivers' knowledge of immunization ( $\mathrm{p}=$ $0.853)$, neither was the association of More than half $161(52.1 \%)$ of the caregivers with female index children having good knowledge of immunization compared to $151(45.6 \%)$ of those with male children. $(\mathrm{p}=0.214)$. Two hundred and fifty-two $(50.7 \%)$ of the caregivers who delivered in hospitals had good knowledge of immunization compared to 53 (44.2\%) of those who delivered at home. This association was also not statistically significant $(p=0.230)$ and this was also the case among $10(58.8 \%)$ of the single caregivers who had good knowledge of immunization compared to 299 (48.6\%) of those who were married. $(p=0.655)$. One hundred and eighty-seven $(52.4 \%)$ of caregivers with household sizes of $5-8$ had good knowledge of immunization compared to $8(42.1 \%)$ of those with household sizes of 9 or more. This association was statistically significant $(\mathrm{p}=0.021)$. Twenty-two $(81.5 \%)$ of the caregivers with tertiary level of education had good knowledge of immunization compared to $41(48.2 \%)$ of those with no formal education. This association was also statistically significant $(\mathrm{p}=0.042)$.

\begin{tabular}{lcc} 
Table 2: Mothers/caregivers' knowledge of immunization \\
\hline Variable & $\begin{array}{l}\text { Frequency } \\
(\mathbf{n}=\mathbf{6 4 0 )}\end{array}$ & Percent \\
\hline $\begin{array}{l}\text { Awareness of immunization } \\
\text { Aware }\end{array} 640$ & 100.0
\end{tabular}

\begin{tabular}{|c|c|c|}
\hline \multicolumn{3}{|l|}{ Source of information* } \\
\hline Healthcare practitioner & 607 & 94.8 \\
\hline Media & 498 & 77.8 \\
\hline Friends & 435 & 68.0 \\
\hline Relatives & 344 & 53.8 \\
\hline \multicolumn{3}{|l|}{ Vaccine mentioned* } \\
\hline BCG & 570 & 89.1 \\
\hline OPV & 570 & 89.1 \\
\hline HBV & 478 & 74.7 \\
\hline DPT & 452 & 70.6 \\
\hline PENTA & 423 & 66.1 \\
\hline Measles & 335 & 52.3 \\
\hline PCV & 315 & 49.2 \\
\hline Yellow fever & 315 & 49.2 \\
\hline \multicolumn{3}{|c|}{ Number of vaccines mentioned } \\
\hline 0 & 66 & 10.3 \\
\hline $1-6$ & 259 & 40.5 \\
\hline$\geq 7$ & 315 & 49.2 \\
\hline \multicolumn{3}{|c|}{ Knowledge of expected age of completion } \\
\hline 9 months & 610 & 95.3 \\
\hline 12 months & 17 & 2.7 \\
\hline 15 months & 6 & 0.9 \\
\hline 18 months & 7 & 1.1 \\
\hline \multicolumn{3}{|c|}{ Knowledge of the purpose of immunization } \\
\hline Makes child brilliant & 16 & 2.5 \\
\hline Prolongs life & 18 & 2.8 \\
\hline Prevents diseases & 585 & 91.4 \\
\hline Makes child grow fast & 21 & 3.3 \\
\hline
\end{tabular}

All mothers/caregivers had heard about routine childhood vaccines under the national immunization schedule. This finding is in tandem with the observation in a study done in Lagos, where also high maternal awareness of immunization was recorded. (Odusanya et al, 2009) However, the current finding is in contrast with that contained in a study done in Ambo, Ethiopia (Birhann et al., 2015) where the awareness of immunization was poor. This disparity 
between findings in this study and the Ethiopian study may be due to the differences in information, education and communication (IEC) programmes of the two countries or due to the location and accessibility of the mothers to health care services. Majority of the respondents in the Ethiopian study were in the rural areas while this study was made up of respondents from both urban and rural areas.

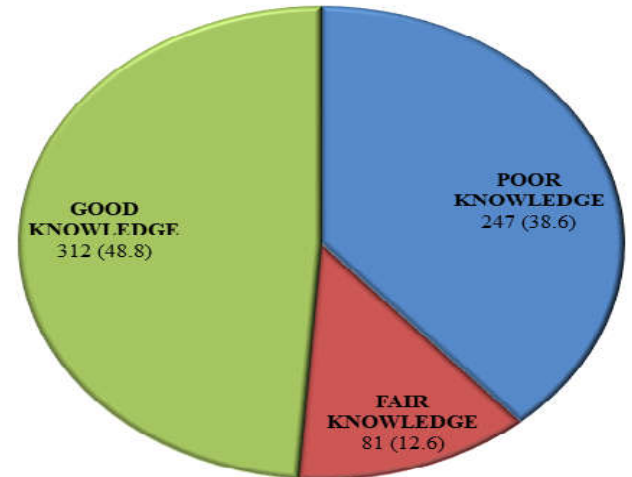

Fig 1: Composite score for caregivers' knowledge of immunization

All mothers/caregivers knew about BCG and OPV vaccines. This level of awareness for these vaccines noted in this study is higher than the level of awareness of OPV reported from Niger (Kobayashi et al., 2003) but comparable to the high level of awareness of same vaccines in in Nairobi, Kenya (Kamau and Esamai, 2009) This finding can be attributable to the National Supplementary Immunization plus days which is aimed at improving coverage for OPV and eradicating the polio disease from the Integrated Diseases, Surveillance and Response (IDSR). The constant jingles being aired on television and radio to improve utilization of immunization and also proximity of the time of delivery to the vaccine scheduled early in the NPI schedule may also have contributed to the high level of awareness for OPV.

Awareness level for recently introduced vaccines, such as pentavalent vaccine, pneumococcal conjugate vaccine, and those given at the end of the immunization schedule (measles and yellow fever vaccines), were slightly lower compared to the other vaccines in the routine immunization schedule. This observation could be as a result of time lag between the two sets of vaccines which could cause mothers to forget the measles vaccine and dropout or not follow through with subsequent doses. Just as the vast majority of the people have been sensitized with regards to OPV, other vaccines should also be given similar have treatment. Such enlightenment requires health promotion in the form of health education
Table 3: mothers' practice of immunization

\begin{tabular}{|c|c|c|}
\hline Variable & $\begin{array}{l}\text { Frequency } \\
(\mathrm{n}=640)\end{array}$ & Percent \\
\hline \multicolumn{3}{|l|}{ Ever vaccinated child } \\
\hline Yes & 640 & 100.0 \\
\hline No & 0 & 0.0 \\
\hline \multicolumn{3}{|l|}{$\begin{array}{l}\text { Possession of vaccination } \\
\text { card }\end{array}$} \\
\hline Yes and seen & 625 & 97.7 \\
\hline Yes but not seen & 15 & 2.3 \\
\hline No & 0 & 0.0 \\
\hline \multicolumn{3}{|c|}{ Vaccination coverage based on age* } \\
\hline $\mathrm{BCG}(\mathrm{n}=640)$ & 630 & 98.4 \\
\hline OPV1 $(\mathrm{n}=640)$ & 640 & 100.0 \\
\hline OPV2 $(n=520)$ & 520 & 100.0 \\
\hline OPV3 (n = 399) & 398 & 99.7 \\
\hline PENTA1 $(n=640)$ & 640 & 100.0 \\
\hline PENTA2 $(\mathrm{n}=520)$ & 520 & 100.0 \\
\hline PENTA3 $(\mathrm{n}=399)$ & 359 & 90.0 \\
\hline PCV1 $(n=640)$ & 640 & 100.0 \\
\hline PCV2 $(n=520)$ & 505 & 97.1 \\
\hline PCV3 (n = 399) & 338 & 84.7 \\
\hline Measles $(n=163)$ & 118 & 72.4 \\
\hline Yellow fever $(n=163)$ & 119 & 73.0 \\
\hline
\end{tabular}

where persuasive communications are utilized in passing the information on to the people. The message in such a manner that the content is comprehended and accepted by the people with the effect that mothers are urged to present their wards for immunization including those given late in the NPI schedule. This high level of caregiver's awareness of immunization could have resulted from the aggressive health education carried out by health workers in health care centers, to peer group influence and general community participation in routine immunization. This is corroborated by the finding that healthcare practitioners were the commonest source of information followed by the mass media and friends.

The current finding is consistent with the study done in Addis Ababa where health workers were also the main source of information. (Birhann et al., 2015).

This trend may be attributed to the fact that vaccination information is usually given to mothers by healthcare professional just before giving vaccines to the children during each immunization sessions and postnatal visits. The finding is further substantiated by findings noted in studies done in Nigeria (Odusanya et al, 2009; Ibraheem et al., 2016) and Saudi Arabia. (Yousif et al., 2013) Friends and family members were also noted as important sources of information on immunization but their knowledge of immunization needs to be strengthened. 
Table 4: knowledge of immunization and the socio-demographic characteristics of index child and their caregivers

\begin{tabular}{|c|c|c|c|c|c|}
\hline \multirow[t]{2}{*}{ Variable } & \multicolumn{3}{|c|}{ Knowledge of immunization } & \multirow[t]{2}{*}{ Test statistic } & \multirow[t]{2}{*}{ p value } \\
\hline & $\begin{array}{l}\text { Poor }(247) \\
\text { n }(\%)\end{array}$ & $\begin{array}{l}\text { Fair (81) } \\
\text { n (\%) } \\
\end{array}$ & $\begin{array}{l}\text { Good (312) } \\
\text { n (\%) }\end{array}$ & & \\
\hline \multicolumn{6}{|l|}{ Child age (months) } \\
\hline $0-5$ & $185(38.8)$ & $59(12.4)$ & $233(48.8)$ & $F=2.636$ & 0.853 \\
\hline $6-11$ & $53(40.5)$ & $16(12.2)$ & $62(47.3)$ & & \\
\hline $12-17$ & $7(25.9)$ & $5(18.5)$ & $15(55.6)$ & & \\
\hline $18-23$ & $2(40.0)$ & $1(20.0)$ & $2(40.0)$ & & \\
\hline \multicolumn{6}{|l|}{ Sex of index child } \\
\hline Male & $138(41.7)$ & $42(12.7)$ & $151(45.6)$ & $\chi^{2}=3.084$ & 0.214 \\
\hline Female & $109(35.3)$ & 39 (12.6) & $161(52.1)$ & & \\
\hline \multicolumn{6}{|l|}{ Place of delivery } \\
\hline Hospital & $182(36.6)$ & $63(12.7)$ & $252(50.7)$ & $\chi^{2}=5.610$ & 0.230 \\
\hline Home & $52(43.3)$ & $15(12.5)$ & $53(44.2)$ & & \\
\hline TBA & $13(56.5)$ & $3(13.0)$ & $7(30.4)$ & & \\
\hline \multicolumn{6}{|l|}{ Age (years) } \\
\hline$<20$ & $4(57.1)$ & $0(0.0)$ & $3(42.9)$ & $\mathrm{F}=19.194$ & 0.038 \\
\hline $20-29$ & $93(40.1)$ & $41(17.7)$ & $98(42.2)$ & & \\
\hline $30-39$ & $131(39.5)$ & $29(8.7)$ & $172(51.8)$ & & \\
\hline $40-49$ & $17(28.8)$ & $10(16.9)$ & $32(54.2)$ & & \\
\hline $50-59$ & $0(0.0)$ & $0(0.0)$ & $3(100.0)$ & & \\
\hline$\geq 60$ & $2(28.6)$ & $1(14.3)$ & $4(57.1)$ & & \\
\hline \multicolumn{6}{|l|}{ Marital status } \\
\hline Single & $4(23.5)$ & $3(17.6)$ & $10(58.8)$ & $F=6.006$ & 0.655 \\
\hline Married & $238(38.7)$ & $78(12.7)$ & $299(48.6)$ & & \\
\hline Cohabiting & $1(100.0)$ & $0(0.0)$ & $0(0.0)$ & & \\
\hline Separated/divorced & $3(75.0)$ & $0(0.0)$ & $1(25.0)$ & & \\
\hline Widowed & $1(33.3)$ & $0(0.0)$ & $2(66.7)$ & & \\
\hline \multicolumn{6}{|l|}{ Household size } \\
\hline$\leq 4$ & $108(40.9)$ & $39(14.8)$ & $117(44.3)$ & $\chi^{2}=11.590$ & 0.021 \\
\hline $5-8$ & $134(37.5)$ & $36(10.1)$ & $187(52.4)$ & & \\
\hline$\geq 9$ & $5(26.3)$ & $6(31.6)$ & $8(42.1)$ & & \\
\hline \multicolumn{6}{|l|}{ Level of education } \\
\hline No formal education & $35(41.2)$ & $9(10.6)$ & $41(48.2)$ & $\chi^{2}=13.085$ & 0.042 \\
\hline Primary & $142(38.8)$ & $48(13.1)$ & $176(48.1)$ & & \\
\hline Secondary & $66(40.7)$ & $23(14.2)$ & $73(45.1)$ & & \\
\hline Tertiary & $4(14.8)$ & $1(3.7)$ & $22(81.5)$ & & \\
\hline \multicolumn{6}{|l|}{ Socioeconomic status } \\
\hline Class I & $0(0.0)$ & $0(0.0)$ & $2(100.0)$ & $F=9.782$ & 0.242 \\
\hline Class II & $5(22.7)$ & $1(4.5)$ & $16(72.7)$ & & \\
\hline Class III & $54(41.5)$ & $20(15.4)$ & $56(43.1)$ & & \\
\hline Class IV & $132(40.6)$ & $40(12.3)$ & $153(47.1)$ & & \\
\hline Class V & $56(34.8)$ & $20(12.4)$ & $85(52.8)$ & & \\
\hline
\end{tabular}

More than three quarters of the caregivers received information on immunization from the media (television, radio, internet and newspapers). Television is an important source of health information because it is available in most homes and it is more convenient for caregivers to watch medical programmes than use the internet or obtain information by reading. The study revealed good knowledge of immunization among the caregivers with regards to true purpose of immunization and age of completion of vaccination. This value noted in this study are higher than those obtained in a study involving a rural Nigeria community and Ethiopia (Birhann et al., 2015) where only half of the mothers mentioned correctly the time of completing immunization (at nine months or before the first birth day). The variation in these findings noted between this study and others may be due to the difference in characteristics of the study participants 'particularly educational attainment since about $70 \%$ of mothers included in the study in rural Nigeria were illiterates, higher than the illiteracy rates in this study. Most of the caregivers in the other study had at least primary school education. Despite the fact that caregivers had good knowledge of the age and time of completion of vaccination, few caregivers felt that routine immunization improves the growth and intelligence of children. A similar find has been noted among mothers involved in the rural Nigeria study ${ }^{8}$ where it was observed that less than a quarter of the respondents correctly stated the purpose of immunization but in contrast with findings from an Enugu based study (Tagbo, et al., 2012) where majority of the respondents mentioned the purpose of immunization correctly. The implication of this is that though some had incorrect knowledge of immunization they nevertheless regarded immunization to be beneficial. 
Table 5: Bivariate regression analysis of the predictors of caregivers' knowledge of immunization

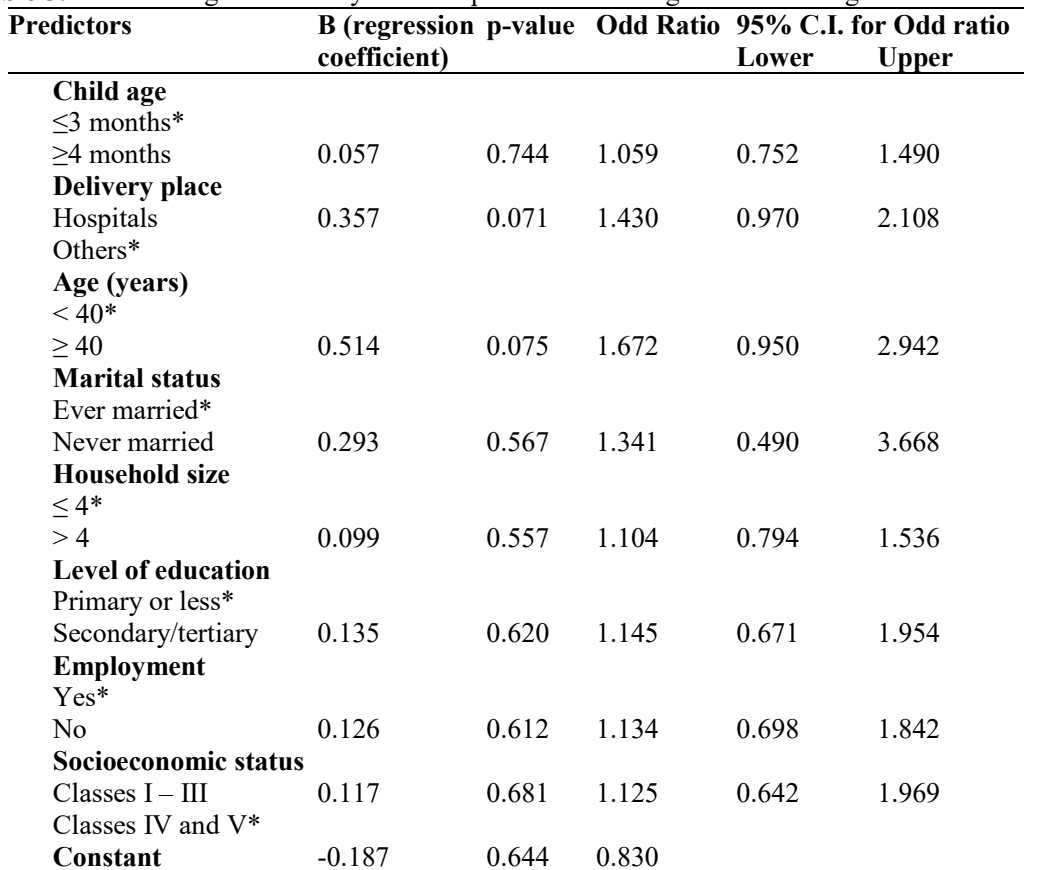

*Reference category, Coefficient of determination $\left(R^{2}\right)=1.4 \%-1.9 \%$; C.I = confidence interval; There were no statistically significant predictors of knowledge of immunization among the socio-demographic characteristics of the respondent Which shows that for every increase in age of the child there was no increase in the caregiver's knowledge of routine immunization with a $p=0.744$ with odds of 1.059 (0.752-1.490)

Health workers could leverage on the observed trend to educate the mothers on the true essence of immunization and its added benefits through the correct use of information, education, and communication materials available on immunization as a rationale for immunization rather than use only images of children known to have suffered from vaccine preventable diseases/ historic images relating to disease outbreaks. Over half of the mothers/caregivers were unaware of the full range of vaccines routinely administered to children in Nigeria. This observation is worrisome as it may suggest that immunization campaigns are suboptimal in spite of the WHO 2010 plan to improve massive cross regional vaccination campaigns. (FMOH, 2011)There could therefore be some knowledge gaps warranting the need for improved health education during antpostnatal care and immunization activities, perhaps using improved community participation, mass mobilization, and retraining of community health workers.

The significantly higher level of knowledge found amongst mothers/caregivers with secondary and higher level of education is expected as they are better placed to understand relevant health information more readily than those with lower level of education. An optimal female literacy level is desirable as this could lead to comprehension of exposure to other social and cultural factors that influence utilization of routine immunization services. Higher educational level was also associated with enhanced knowledge of routine immunization as noted in this study. This may partly be attributed to the quality of information provided to mothers at the health facilities (both during antenatal and immunization clinics by health workers) comprehended better by this cohort of mothers/ caregivers.

All the caregivers reported vaccinating the index child and presented their vaccination cards. Most of the index children were completely immunized for age with an immunization coverage of eight five percent. Similar rates had been reported in India (Hamid et al., 2012) and Ethiopia (Lakew et al., 2015) where majority of the children were completely immunized for age. The current finding is however at variance with the lower immunization rates of less than twentyfive percent obtained from some Nigeria studies (FMOH, 2008; FMOH, 2011) and another carried out in Ethiopia (Etana and Derressa, 2012). The discrepancy in coverage rates may be due to social and cultural factors. Nonetheless the high coverage rate noted among the children in this study is in excess of the goals of the Global Immunization Vision and Strategy (GIVS) which set at least $80 \%$ vaccination coverage in every district.(FMOH,2011) The coverage rate of $85 \%$ noted in this study is different from values 
obtained in a study carried out in Edo State where immunization coverage according to the NDHS 2013, was $52 \%$ and other studies conducted in the Southern part of Nigeria that also fell short of the GIVS goal. The disparity in immunization coverage within the country may reflect the variation in effectiveness of immunization campaign in various localities outside other influences as vaccine supplies, level of literacy, employment and poverty.

Conclusion: knowledge and practice of immunization in this study was good although they were not as significant to what was expected due to the rigorous health education which occurs before immunization sessions daily and the yearly routine and supplementary immunization campaign by the federal and state government, also emphasis need to be given to educating and empowering the girl child and also raising awareness on family planning to enable improvement in the immunization coverage.

\section{REFERENCES}

Salah, AA; Nega Bakari, GE; Godana, W (2015). Evaluation of the quality of Expanded Program on Immunization service delivery in Primary Health Care Institutions of Jigjiga Zone Somali Region, Eastern Ethiopia. European Journal of Preventive Medicine. 3 (4):117-123

Ekure, EN; Esezobor, CI; Balogun, MR; MukhtarYola, M; Ojo, OO; Emodi, IJ (2013). Community Knowledge, Attitude and Practice of Childhood Immunization in Southwest Nigeria. Niger $J$ Paed. 40 (2):106 -111.

Zangeneh, TT; Baracco, G; Al-Tawfiq, JA (2011). Impact of Conjugate Pneumococcal Vaccines on the Changing Epidemiology of Pneumococcal Infections. Expert Rev Vaccines. 10: 345-53.

Federal Ministry of Health. (2009). National Immunization Policy and Standard of Practice. Abuja: Federal Ministry of Health. 16.

Scott, S; Odutola, A; Mackenzie, G; Fulford, T; Afolabi, MO; Jallow, YL; Jasseh, M (2014). Coverage and Timing of Children Vaccination: An Evaluation of the Expanded Programme on Immunization In The Gambia. 9(9):1-9.

Adedire, EB; Ajayi, I; Fawole, IO; Ajumobi, O; Kassasa, S; Wassawa, P (2016). Immunization Coverage and Its Determinants among Children Aged 12-23 Months in Atakumosa-West District Osun State Nigeria. Biomed Central Public Health. 16:905
Sadoh, AE; Eregie, OC (2009). Timeliness and Completion Rate of Immunization among Nigerian Children Attending a Clinic-Based Immunization Service. J Health Popul Nutr. 27(3):391-395

Abdulhareem, I; Onajole, AT; Jimoh, A; Oladipo, AR (2011). Reasons for Incomplete Vaccination and Factors for Missed Opportunities among Rural Children. J. Public Health. Epid. 3 (4):194-203.

Matua, MK; Kimani-Murage, E; Ngomi, N; Rayn, H; Mwanikii, P; Echoka, E (2016). Fully Immunized Child; Coverage, Timing And Sequencing of Routine Immunization in Urban Poor Settlement in Nairobi. Trop. Med. Health. 44 (13):1-12.

Hannan, AA (2014). Maternal Satisfaction about Childhood Immunization in Primary Health Centre. Pan African Medical Journal. 18:157

Onsomu, E; Abuya, BA; Okech, NI (2015). Maternal Education and Immunization Status among Children in Kenya. Child Health Journal. 19(8):1724-33

Maina, LC; Karanja, S; Kombichi, J (2013). Immunization Coverage and Its Determinants among Children Aged 12-23 Months in PeriUrban Area. Pan Afr. Med. J. 14(3):21-81

Subani, S; Yassen, R; Khan, MA; Jeelani, G; Rida, F (2015). Impact of Mother's Education on Child Immunization. Journal of Finance and Economics. 3(3):51-54

Uzochukwu, BS; Onwujekwe, OE; Akpala, CO (2004). Community Satisfaction With The Quality Of Maternal And Child Health Services In South East Nigeria. East African Medical Journal. 81(6):293-299.

Paediatric Association of Nigeria (2012). Recommended Routine Immunization Schedule For Nigerian Children. Niger J Paed. 39(40):15258.

Beaven, A; Atienza, BS; Abing, VT; Phoebe, A; Gallepso, T (2016). Maternal Constraints towards Compliance to Expanded Program On Immunization. Journal of Nursing and Health Care. 3(2):30-38.

Nisar, N; Mirza, M; Qadri, MH (2010). Knowledge, Attitude And Practices Of Mothers Regarding Immunization Of One-Year Old Children At 
Mawatch Goth, Kemari Town, Karachi. Pak J Med Sci. 26(1):183-186.

National Population Commission And Icf International (2013). Nigeria Demographic And Health Survey Abuja, Nigeria: Npc And Icf International. 92-153

Cochrane WG (1977). Sampling Techniques, 3rd Edition. New York: John Wiley And Son.

Adefolalu, OA; Kanma-Okafo, OJ; Balogun, MR (2019). Maternal Knowledge, Attitude And Compliance Regarding Immunization Of Under Five Children In Primary Health Care Centres In Ikorodu Local Government Area, Lagos State. $J$ Clin Sci. 16(1):7-14

Odusanya, OO; Alufohai, EF; Meurice, FP; Ahonkai, VI (2008). Determinants of Vaccination Coverage in Rural Nigeria. Bmc Public Health. 8:381.

Birhanu, S; Anteneh, A; Kibie, Y; Jejaw A (2015). Knowledge, Attitude and Practice of Mothers towards Immunization of Infants in Health Centres at Addis Ababa, Ethiopia. American Journal of Health Research. 4(1):6-17.

Kobayashi, M; Hirakawa, K; Sawada, M; Suzuki, C; Saikawa, S; Ando, H; Nakame, M; Nakano, T (2003). Vaccination Coverage of Poliomyelitis among Less Than 5-Year Old Children in the Markets of Niger. Jpn J Infect Dis. 56: 175-77.

Kamau, N; Esamai, FO (2009). Determinants of Immunisation Coverage among Children in Mathare Valley, Nairobi. East Afr Med J. 78: 590594.

Ibraheem, RM; Bello, AO; Adeboye, MA; Adeyeba, DT; Mohammed, MJj (2016). Missed Vaccination Opportunities Of A Secondary Health Facility In Ilorin Nigeria. J. Comm. Med. Primary Health Care. 28(1):31-37
Youssif, MA; Albaraq, AA; Abdallah, MA; Elbur, AI (2013). Parents' Knowledge and Attitude on Childhood Immunization Saudi Arabia. J Vaccine Vaccine. 5(1):215

Tagbo, BN; Uleanya, ND; Nwokoye, IC; Eze, JC; Omotowo, IB (2012). Mothers' Knowledge, Perception and Practice of Childhood Immunization in Enugu. Niger J Paed. 39 (3):9096

Hamid, S; Jabeen, R; Andrabi, SA; Fazil, A (2012). Immunization of Children in A Rural Area Of North Kashmir, India: A Kap Study. Journal of Health and Allied Sciences. 11(1):10.

Lakew, Y; Bekele, A; Biadgilign, S (2015). Factor's Influencing Full Immunization Coverage Among 12-23 Months of Age Children in Ethiopia: Evidence from the National Demographic and Health Survey In 2011. Bmc Public Health. 15(1):728.

Federal Ministry of Health, Nigeria (2008). Technical Report on National Hiv Sero-Prevalence Rate Among Ante Natal Care Patients In Nigeria. National Aids/Std Control Programme. Fmoh. 1343.

Federal Ministry of Nigeria (2011). Comprehensive Epi Multi- Year Plan 2011-2015. National Primary Health Care Development Agency.

Etana, B; Deressa, W (2012). Factors associated with complete immunization coverage in children Aged 12-23 months in Ambo Woreda, Central Ethiopia. BMC Public Health. 12:566. 